\title{
Preferences for Physician Roles in Follow-up Care During Survivorship: Do Patients, Primary Care Providers, and Oncologists Agree?
}

\author{
Archana Radhakrishnan, MD, MHS' , M. Chandler McLeod, PhD, MS ${ }^{7}$, Ann S. Hamilton, PhD, MA², \\ Kevin C. Ward, PhD, MPH ${ }^{3}$, Steven J. Katz, MD, MPH ${ }^{1,4}$, Sarah T. Hawley, PhD, MPH ${ }^{1,4,5}$, and \\ Lauren $P$. Wallner, $P h D, M P H^{1,6}$ \\ 'Department of Internal Medicine, University of Michigan, Ann Arbor, MI, USA; ${ }^{2}$ Department of Preventive Medicine, Keck School of Medicine, \\ University of Southern California, Los Angeles, CA, USA; ${ }^{3}$ Department of Epidemiology, Emory University, Atlanta, GA, USA; ${ }^{4}$ Department of Health \\ Management and Policy, University of Michigan, Ann Arbor, MI, USA; ${ }^{5}$ Ann Arbor VA Center of Excellence in Health Services Research \& \\ Development, Ann Arbor, MI, USA; ${ }^{6}$ Department of Epidemiology, University of Michigan, Ann Arbor, MI, USA.
}

$\mathrm{J}$ Gen Intern Med 34(2):184-6

DOI: $10.1007 / \mathrm{s} 11606-018-4690-5$

(C) Society of General Internal Medicine 2018

\section{INTRODUCTION}

National organizations recommend team-based care, where cancer specialists and primary care providers (PCPs) work together to provide coordinated care to patients after completing cancer treatment (i.e., during survivorship). ${ }^{1,2}$ This includes services such as managing comorbidities, performing routine health maintenance, primary cancer surveillance and secondary cancer screening. The adoption of team-based care models has lagged, in part, due to uncertainty around whether the oncologist or PCP should manage these services. ${ }^{3}$ Prior studies reported that while $51 \%$ of PCPs support a shared-care model, nearly $60 \%$ of oncologists prefer that oncologists direct this care. Our work shows that a notable minority of women with early-stage breast cancer preferred their oncologist handle their primary care during survivorship. ${ }^{4}$ Better alignment of patient and provider preferences for physician roles during survivorship is necessary to support effective implementation of team-based care models. However, contemporary studies assessing patient and provider alignment for team-based care models do not exist. ${ }^{2}, 5$ Therefore, we examined the agreement between patients, oncologists, and PCPs for which physician type each preferred to lead various services during survivorship.

\section{METHODS}

The iCanCare study is a population-based survey of women with early-stage breast cancer diagnosed between 2014 and 2015. ${ }^{4}$ Women from the Los Angeles and Georgia SEER registries $(N=3672)$ completed surveys 8 months after diagnosis (response rate $68.1 \%, N=2502$ ). Respondents

Published online October 3, 2018 identified their medical oncologist and PCP who were subsequently surveyed $(N=414$ oncologists and 852 PCPs,

Table 1 Sample Characteristics

\begin{tabular}{|c|c|}
\hline & $\begin{array}{l}\text { Weighted \% or } \\
\text { Mean (SD) }\end{array}$ \\
\hline Patients & Within $N=237$ triads \\
\hline Age & $61.3(11.4)$ \\
\hline \multicolumn{2}{|l|}{ Race } \\
\hline White & 69.1 \\
\hline Black & 17.2 \\
\hline Hispanic & 6.6 \\
\hline Asian & 6.9 \\
\hline Unknown & 0.2 \\
\hline \multicolumn{2}{|l|}{ Education } \\
\hline High school or less & 23.1 \\
\hline Some college & 37.0 \\
\hline College graduate or more & 39.8 \\
\hline \multicolumn{2}{|l|}{ Cancer stage } \\
\hline 0 & 21.2 \\
\hline I & 52.3 \\
\hline II & 26.5 \\
\hline \multicolumn{2}{|l|}{ Surgical treatment } \\
\hline Breast conserving surgery & 68.7 \\
\hline Unilateral mastectomy & 11.6 \\
\hline Bilateral mastectomy & 19.7 \\
\hline \multicolumn{2}{|l|}{ SEER site } \\
\hline Georgia & 74.4 \\
\hline Los Angeles County & 25.6 \\
\hline Primary care physicians & $N=190$ \\
\hline Years in practice & $21.2(9.4)$ \\
\hline Male gender & 50.8 \\
\hline \multicolumn{2}{|l|}{ Number of new breast cancer patients/year } \\
\hline$\leq 10$ & 85.5 \\
\hline $11-15$ & 6.6 \\
\hline$\geq 16$ & 7.9 \\
\hline \multicolumn{2}{|l|}{ Practice type } \\
\hline Large group or $\mathrm{HMO}$ & 21.1 \\
\hline $\begin{array}{l}\text { Other (academic, community health clinic, } \\
\text { private practice, other) }\end{array}$ & 78.9 \\
\hline Oncologists & $N=116$ \\
\hline Years in practice & $16.1(10.7)$ \\
\hline Male gender & 59.9 \\
\hline \multicolumn{2}{|l|}{ Number of new breast cancer patients/year } \\
\hline$<21$ & 13.4 \\
\hline $21-50$ & 30.6 \\
\hline$>50$ & 49.9 \\
\hline \multicolumn{2}{|l|}{ Practice type } \\
\hline Integrated or government-facility & 15.4 \\
\hline $\begin{array}{l}\text { Other (private practice, academic, non- } \\
\text { academic health system, outside management } \\
\text { agreement) }\end{array}$ & 84.6 \\
\hline
\end{tabular}



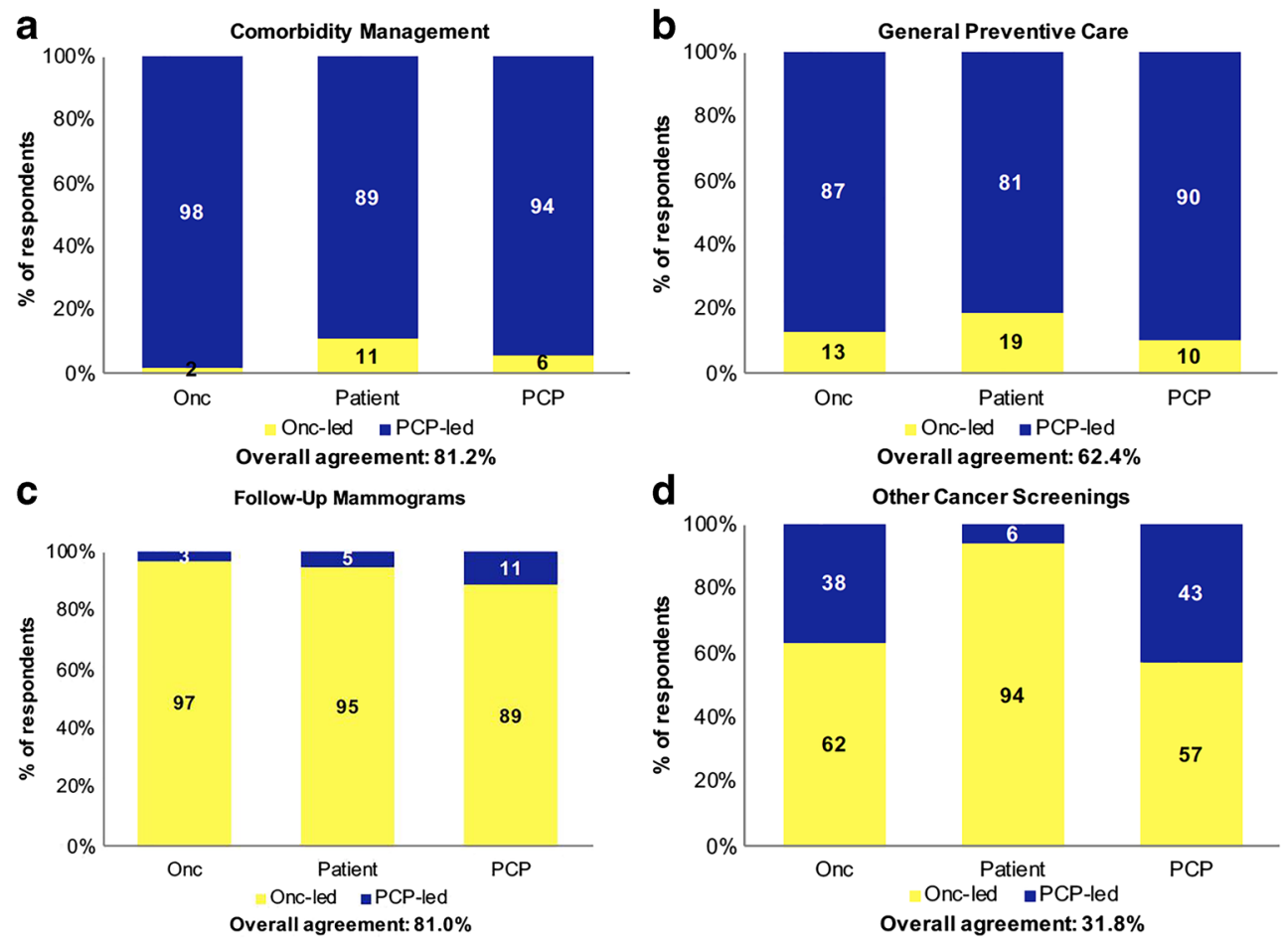

Figure 1 Patient, PCP, and oncologist preferences for physician roles for each aspect of follow-up care during survivorship.

response rates $63.0 \%$ and $60.8 \%$ respectively), leading to 237 triads of patients, oncologists, and PCPs. Patients and providers were asked the same set of questions regarding preferences for which physician should handle comorbidity management, general preventive care, follow-up mammograms, and other cancer screenings during survivorship. Responses included "prefer oncologist," "prefer PCP," "either," or "both," which were categorized as prefer oncologist-led vs. prefer PCP-led (PCP/both/either). We tabulated the distribution of preferences for oncologist- vs. PCP-led care for each service and calculated the overall agreement within the triad for each service. We also performed sensitivity analyses to account for clustering at the physician level using Rao Scott chi-square tests, which yielded similar results (not shown). For the service with the lowest overall agreement (other cancer screenings), we examined the proportion of respondents who both preferred oncologist- or PCP-led care among pairs of PCPs and patients, oncologists and patients, and PCPs and oncologists to identify where agreement was lowest.

\section{RESULTS}

Table 1 describes the sample characteristics. Within the 237 triads of patients, oncologists, and PCPs, the majority preferred PCPs handle comorbidities ( $89 \%$ vs. $98 \%$ vs. $94 \%$ respectively) and provide general preventive care ( $81 \%$ vs. $87 \%$ vs. $90 \%$ respectively), and oncologists handle follow-up mammograms (95\% vs. $97 \%$ vs. $89 \%$ respectively) and other cancer screenings ( $94 \%$ vs. $62 \%$ vs. $57 \%$ respectively)
(Fig. 1). Overall agreement was highest for comorbidity management $(81.2 \%)$ and follow-up mammograms $(81.0 \%)$, moderate for general preventive care $(62.4 \%)$, and lowest for other cancer screenings $(31.8 \%)$.

Within other cancer screenings, $60.5 \%$ of patients and oncologists and $55.9 \%$ of patient and PCPs agreed on which physician should handle this service, while $46.5 \%$ of oncologists and PCPs agreed (data not shown).

\section{DISCUSSION}

While patients, PCPs, and oncologists largely agreed on which physician should handle comorbidity management, general preventive care, and follow-up mammograms during survivorship, there was notable disagreement in preferences for who should screen for other cancers, primarily between PCPs and oncologists.

Prior research suggests that oncologists lack trust in PCPs' ability to deliver survivorship care, which may prompt them to provide the service themselves. ${ }^{3}$ Surprisingly, we found that more than half of PCPs in this sample preferred that oncologists screen for other cancers, a service routinely provided in primary care. PCPs have reported a lack of education and training in survivorship care, which may contribute to their reluctance to deliver screening services for breast cancer survivors. ${ }^{6}$ It is also possible that PCPs perceive that patients with a history of breast cancer are at higher risk for subsequent cancers and therefore warrant oncology involvement in these services. 
Our results suggest that clarifying physician roles during breast cancer survivorship is necessary both between patients and physicians, but also among physicians themselves. Clinical guidelines and policy provisions that better delineate PCP and oncologist roles may be necessary to promote the delivery of effective team-based survivorship care.

Corresponding Author: Archana Radhakrishnan, MD, MHS; Department of Internal Medicine, Unversity of Michigan, Ann Arbor, MI, USA (e-mail: arra@med.umich.edu).

\section{Compliance with Ethical Standards:}

Conflict of Interest: The authors declare that they do not have a conflict of interest.

\section{REFERENCES}

1. Institute of Medicine, National Research Council. From Cancer Patient to Cancer Survivor. Washington, D.C.: National Academies Press; 2005. https://doi.org/10.17226/11468.
2. Committee on Improving the Quality of Cancer Care: Addressing the Challenges of an Aging Population, Board on Health Care Services, Institute of Medicine, et al. Delivering High-Quality Cancer Care: Charting a New Course for a System in Crisis. Levit L, Balogh E, Nass S, Ganz PA, eds. December 2013. https://doi.org/10.17226/18359.

3. Cheung WY, Aziz N, Noone A-M, et al. Physician preferences and attitudes regarding different models of cancer survivorship care: a comparison of primary care providers and oncologists. J Cancer Surviv. 2013;7(3):343-354. https://doi.org/10.1007/s11764-013-0281-y.

4. Wallner LP, Li Y, Furgal AKC, et al. Patient preferences for primary care provider roles in breast cancer survivorship care. J Clin Oncol. 2017;35(25):2942-2948. https://doi.org/10.1200/JCO.2017.73.1307.

5. Cheung WY, Neville BA, Cameron DB, Cook EF, Earle CC. Comparisons of patient and physician expectations for cancer survivorship care. J Clin Oncol. 2009;27(15):2489-2495. https://doi.org/10.1200/JCO.2008.20. 3232.

6. Dossett LA, Hudson JN, Morris AM, et al. The primary care provider (PCP)-cancer specialist relationship: a systematic review and mixedmethods meta-synthesis. CA Cancer J Clin. 2017:67(2):156-169. https://doi.org/10.3322/caac.21385. 